Research Paper

\title{
Quantitative Proteomic Analysis and Evaluation of the Potential Prognostic Biomarkers in Cholangiocarcinoma
}

\author{
Zengwei Tang ${ }^{1 *}$, Yuan Yang ${ }^{1 *}$, Jinduo Zhang1,2, Wenkang Fu' ${ }^{1}$, Yanyan Lin², Gang $\mathrm{Su}^{3}$, Yan $\mathrm{Li}^{4}$, Wenbo \\ Meng ${ }^{1,2}$, Xun Li1 ${ }^{1,5}$, Xiaodong $\mathrm{Xie}^{3^{\boxplus}}$ \\ 1. The First Clinical Medical School of Lanzhou University, Lanzhou 730000, China. \\ 2. Department of Special Minimally Invasive Surgery, The First Hospital of Lanzhou University, Lanzhou 730000, China. \\ 3. School of Basic Medical Sciences, Institute of Genetics, Lanzhou University, Lanzhou 730000, China. \\ 4. Cleveland Clinic, Department of Inflammation and Immunity, Cleveland OHIO 44195, USA. \\ 5. The second department of General Surgery, The First Hospital of Lanzhou University, Lanzhou 730000, China. \\ * These authors contributed equally to this work. \\ $\triangle$ Corresponding authors: Wenbo Meng Department of Special Minimally Invasive Surgery, The First Hospital of Lanzhou University, Lanzhou 730000, China. \\ Tel:+86 1391917 7177; Fax:+96 0931-8622275; E-mail: mengwb@lzu.edu.cn; Xiaodong Xie School of Basic Medical Sciences, Institute of Genetics, Lanzhou \\ University, Lanzhou, China. E-mail: xdxie@lzu.edu.cn
}

(c) The author(s). This is an open access article distributed under the terms of the Creative Commons Attribution License (https://creativecommons.org/licenses/by/4.0/). See http://ivyspring.com/terms for full terms and conditions.

Received: 2018.08.19; Accepted: 2019.05.28; Published: 2019.07.05

\begin{abstract}
Background \& Aims: Cholangiocarcinoma (CCA) patients have poor outcomes since the late diagnosis limits the benefits of surgery therapy and curative treatment options. The present study was designed to screen the biomarkers for CCA patients.

Methods: Quantitative iTRAQ proteomic analysis was used to identify differentially expressed proteins between CCA and pericarcineous tissue. We examined the expression profile of PRDX2, BGN, LUM, and PPP3CA in CCA tissue using immunohistochemistry. We further investigated the correlation between PPP3CA expression and the survival of CCA patients $(n=91)$.

Results: 2,886 confidential proteins were identified by using the iTRAQ technique, 233 of which were differentially expressed. PRDX2, BGN, PPP3CA, and LUM were expressed in CCA tissue, whereas they were not expressed in choledocal cyst tissue except for LUM. PPP3CA was expressed in the cytoplasm of carcinoma cells in 22 cases (24.2\%) of 91 CCA patients. Patients with PPP3CA-positive expression showed a significantly shorter survival period than did non-expressing patients $(P=0.030)$. The univariate analysis showed that tumor size $(P=0.002)$, vascular invasion $(P=0.001)$, histological grading $(P=0.011)$, and PPP3CA expression $(P=$ $0.033)$ were statistically significant risk factors affecting the prognosis of CCA patients. The multivariate analysis demonstrated PPP3CA expression $(P=0.009)$ and vascular invasion $(P=0.012)$ were statistically significant independent risk factors of CCA patients.
\end{abstract}

Conclusions: The results suggested that the expression of PPP3CA in CCA patients is a new independent factor for poor prognosis and a useful prognostic predictor for patients with CCA.

Key words: cholangiocarcinoma, iTRAQ, PPP3CA, prognosis, bioinformarics

\section{Introduction}

Cholangiocarcinoma (CCA), a heterogeneity group of malignancies originating in the epithelia at various anatomic locations in the biliary tree, is the most common primary malignancy of the biliary tract [1]. The median survival for patients with unresectable CCA is less than a year [2]. The prognosis is considerably better for patients who have undergone radical resection of CCA, with five year-survival rates ranging from $20 \%$ to $40 \%$ [3, 4].
The late appearance of its clinical presentation makes CCA difficult to detect at an early stage-even with combining non-specific biomarkers, as well as with using advanced imaging technology. Late diagnosis compromises the effectivity of therapeutic options, which are based on surgical resection and/or liver transplantation; whereas chemotherapies are virtually palliative, given the marked chemoresistance of this cancer $[3,5]$. 
Carbohydrate antigen 19-9 (CA19-9) is widely used as a serological marker of CCA. However, the capability of CA19-9 as a diagnostic marker is limited due to the influence of co-existing inflammation in the biliary tract and due to the fact that carcinoma cells from Lewis-gene-negative cases do not produce CA19-9 [6, 7]. Furthermore, CA19-9 cannot detect the development and progression of CCA [3]. Several specific CCA biomarker studies to overcome these limitations have been performed [8]. Wisteria floribunda agglutinin sialylated-Mucin1 has been identified as a novel diagnostic indicator of CCA in bile with a high specificity in comparison with CA19-9 $[9,10]$. In addition, Mucin1 also has been demonstrated as having prognostic value for CCA patients [11]. However, these biomarkers have also been found to be expressed in other tumors such as breast cancer, pancreatic cancer, etc. [12]. Therefore, it is considered very important to screen suitable prognostic and/or diagnostic biomarkers of CCA, and to discover potential treatment strategies for this intractable disease.

Isobaric tags for relative and absolute quantitation (iTRAQ) are characterized by high proteome coverage and labeling efficiency, and has no side effects on analytical or biochemical properties of the labeled proteins or peptides [13]. Currently, iTRAQ-based quantitative proteomic analysis has been become a promising technology for identifying differentially expressed proteins. The aim of this study is to explore the differentially expressed proteins in paired CCA and pericarcinous tissue by means of iTRAQ technique in combination with liquid chromatography-mass spectrometry (LC-MS), focusing on identifying reliable biomarkers for the prediction of CCA patients' prognosis. Among the differentially expressed proteins identified using iTRAQ-based quantitative proteomic analysis, the expression profile of peroxiredoxin2 (PRDX2), biglycan (BGN), lumican (LUM), and serine/threonine-protein phosphatase $2 \mathrm{~B}$ catalytic subunit alpha isoform (PPP3CA) in primary CCA tissue were examined using immunohistochemistry (IHC) assay. In addition, we found that PPP3CA expression in CCA patients is a very useful predictor for poor prognosis.

\section{Materials and Methods}

\section{Selection of patients and collection of clinical samples}

A total of six matched, fresh primary CCA and the pericarcinous tissues were collected and employed for iTRAQ followed by LC-MS. The clinicopathological features of these patients are summarized in Table 1. Of patients who underwent surgical therapy at The Department of Special Minimally Invasive Surgery, The First Hospital of Lanzhou University from April to June, 2017, all were postoperatively diagnosed as having had primary CCA. Gross appearance and histological type was confirmed by two pathologists in the Department of Pathology of The First Hospital of Lanzhou University.

Table 1. Summary of The Clinicopathological Features of Individual Patients Collected for ITRAQ

\begin{tabular}{|c|c|c|c|c|c|c|}
\hline Code & $\begin{array}{l}\text { Pathology } \\
\text { diagnosis }\end{array}$ & Histopathology & $\begin{array}{l}\text { Lymph } \\
\text { node } \\
\text { metastasis }\end{array}$ & $\begin{array}{l}\text { Gross } \\
\text { appearance }\end{array}$ & $\begin{array}{l}\text { Age } \\
\text { (yrs) }\end{array}$ & Gender \\
\hline 1 & $\begin{array}{l}\text { Extrahepatic } \\
\text { CCA }\end{array}$ & $\begin{array}{l}\text { Moderately } \\
\text { differentiated } \\
\text { adenocarcinoma }\end{array}$ & Positive & Mass-forming & 58 & Male \\
\hline 2 & $\begin{array}{l}\text { Extrahepatic } \\
\text { CCA }\end{array}$ & $\begin{array}{l}\text { Moderately } \\
\text { differentiated } \\
\text { adenocarcinoma }\end{array}$ & Negative & $\begin{array}{l}\text { periductal } \\
\text { infiltrating }\end{array}$ & 72 & Male \\
\hline 3 & $\begin{array}{l}\text { Extrahepatic } \\
\text { CCA }\end{array}$ & $\begin{array}{l}\text { Moderately } \\
\text { differentiated } \\
\text { adenocarcinoma }\end{array}$ & Negative & $\begin{array}{l}\text { periductal } \\
\text { infiltrating }\end{array}$ & 75 & Male \\
\hline 4 & $\begin{array}{l}\text { Extrahepatic } \\
\text { CCA }\end{array}$ & $\begin{array}{l}\text { Poorly } \\
\text { differentiated } \\
\text { adenocarcinoma }\end{array}$ & Positive & $\begin{array}{l}\text { periductal } \\
\text { infiltrating }\end{array}$ & 51 & Male \\
\hline 5 & $\begin{array}{l}\text { Extrahepatic } \\
\text { CCA }\end{array}$ & $\begin{array}{l}\text { Well } \\
\text { differentiated } \\
\text { adenocarcinoma }\end{array}$ & Positive & $\begin{array}{l}\text { intraductal } \\
\text { growing }\end{array}$ & 51 & Female \\
\hline 6 & $\begin{array}{l}\text { Extrahepatic } \\
\text { CCA }\end{array}$ & $\begin{array}{l}\text { Poorly } \\
\text { differentiated } \\
\text { adenocarcinoma }\end{array}$ & Negative & Mass-forming & 55 & Female \\
\hline
\end{tabular}

Furthermore, paraffin-embedded tissues of 5 cases of choledochal cyst, as well as 91 paraffin-embedded CCA cases for immunohistochemistry (IHC), were obtained with informed consent from patients who underwent surgical therapy at The First Hospital of Lanzhou University from 2011 to 2016. The mean age of patients presenting with choledochal cyst was 9.2 years (range: 3-17 years), and all patients with choledochal cyst were confirmed by pathologists postoperatively. For cases of CCA patients, the corresponding clinicopathological parameters are summarized in Table 2. The experimental protocol was approved by the Ethics Committee for Human Research, Lanzhou University. The written consents were received from all participants in this study. The inclusion criteria of patients in this study were as follows: (1) pathologically diagnosed as primary cholangiocarcinoma; (2) without neoadjuvant or adjuvant radiotherapy; (3) underwent a surgical resection; (4) no distant metastasis at first visit; (5) with adequate clinical information and follow-up data; (6) no preoperative and/or postoperative life-threatening complications; and (7) clinical data, including tumor differentiation and $\mathrm{T} / \mathrm{N}$ stage, were available for all patients. The pathological stage of each cancer at the 
time of operation was identified by using the 7th edition of Classification of American Joint Committee on Cancer [4].

Table 2. Clinicopathological Features of CCA Patients

\begin{tabular}{ll}
\hline Age, mean (year, range) & $51.2(32-76)$ \\
Gender (M : F), $\mathbf{n}(\%)$ & $48(52.7): 43(47.3)$ \\
T-stage, (n)\% & $7(7.7)$ \\
T1 & $62(68.1)$ \\
T2 & $19(20.9)$ \\
T3 & $3(3.3)$ \\
T4 & \\
Histological grade, n(\%) & $12(13.2)$ \\
Poorly & $70(76.9)$ \\
Moderate & $9(9.9)$ \\
Well & \\
Lymph node metastasis, n(\%) & $60(65.9)$ \\
N0 & $31(34.1)$ \\
N1 & \\
Vascular invasion, n(\%) & $61(67.0)$ \\
Negative & $30(33.0)$ \\
Positive & \\
Tumor size (cm), n(\%) & $32(35.2)$ \\
$>3.5$ & $59(64.8)$ \\
s3.5 & $11.17(0.13-59.43)$ \\
Median follow up time (months, range)
\end{tabular}

\section{Protein extraction and purification}

Tissue samples were sectioned and thawed on ice. The tissues were ground in liquid nitrogen and extracted with lysis buffer (containing $7 \mathrm{~mol} / \mathrm{L}$ urea, 2 $\mathrm{mol} / \mathrm{L} \quad$ thiourea, $4 \%$ 3-(3-cholamidopropyl) dimethylammonium propane sulfonate (CHAPS), 65 $\mathrm{mmol} / \mathrm{L}$ dithiothreitol, and $0.1 \mathrm{mmol} / \mathrm{L}$ phenylmethylsulfonyl fluoride) combined with $4 \%$ phenylmethanesulfonyl fluoride (PMSF). The samples were then sonicated $(80 \mathrm{~W})$ on ice for $3 \mathrm{~min}(0.8$-second sonication, followed by an 0.8-second break). For protein precipitation, pre-chilled acetone was added to the samples (5ml acetone: $1 \mathrm{ml}$ samples), and the mixture was stored overnight at $-20^{\circ} \mathrm{C}$. The resulting suspension was centrifuged for $10 \mathrm{~min}$ at $12,000 \mathrm{x} \mathrm{g}$ at $4^{\circ} \mathrm{C}$. After removing the supernatant, $2 \mathrm{ml}$ pre-chilled acetone was added to the precipitate, and the mixture was centrifuged twice for $15 \mathrm{~min}$ at $12,000 \times \mathrm{g}$ at $4^{\circ} \mathrm{C}$. The pellet was air dried at room temperature after removing the supernatant. Then the precipitate was dissolved in $0.5 \mathrm{ml} 1 \mathrm{M}$ triethylammonium bicarbonate buffer (TEAB; Sigma-Aldrich, Australia) and centrifuged for $15 \mathrm{~min}$ at room temperature. The supernatant was then transferred to a fresh $1 \mathrm{ml}$ tube, and the protein concentration was quantified by using the Bradford Protein Assay (Tiangen, Beijing, China).

\section{iTRAQ labeling and peptides fractionation}

The iTRAQ Labeling procedures were conducted according to the manufacturer's instructions ( $\mathrm{AB}$ SCIEX, Shanghai, China). 100ug proteins of each group were precipitated with fivefold acetone at $-20^{\circ} \mathrm{C}$ for $1 \mathrm{~h}$. Then, the mixture was centrifuged for $10 \mathrm{~min}$ at $12,000 \times \mathrm{g}$ at $4^{\circ} \mathrm{C}$. After removal of the suspension, the protein was dried using a vacuum centrifuge. Then, the protein was resuspended in $50 \mu \mathrm{l}$ dissolution buffer, reduced by $4 \mu$ reducing reagent for $1 \mathrm{~h}$ at $60^{\circ} \mathrm{C}$, and then alkylated by $2 \mu \mathrm{l}$ cysteine blocking reagent for $10 \mathrm{~min}$ at room temperature. Protein samples were then digested with 50 $\mathrm{\mu l}$ trypsin $(50 \mathrm{ng} / \mu \mathrm{l})$ at $37^{\circ} \mathrm{C}$ for $12 \mathrm{~h}$. Tryptic peptides were dried by vacuum centrifugation and labeled with the iTRAQ regents at room temperature for $2 \mathrm{~h}$. Afterward, 100 $\mu 1$ distilled water was added to stop the reaction, the samples were mixed with equal amounts, and then the dried samples using a vacuum centrifuge were left for isolation and identification.

\section{Strong cation exchange (SCX) chromatography-based fractionation}

SCX chromatography-based fractionation and LC-MS/MS were conducted by Sangon Biotech (Shanghai) Co., Ltd. SCX chromatography was performed as previously described [14]. The peptides were fractionated on an apolysulfoethyl A column $(2.1 \times 150 \mathrm{~mm} 5 \mu \mathrm{m}, 300 \AA$, Poly LC, Columbia, MD, USA) by using an Agilent 1200 HPLC system (Agilent, Beijing, China). Firstly, the mixed peptides, which were dissolved in $110 \mu$ l Nano-RPLC buffer A $(0.1 \%$ formic acid and $2 \% \mathrm{ACN}$ ), were further separated by Agilent 1200 HPLC (Agilent, Beijing, China) on the secondary RP analytical column (Analytical Guard Column $4.6 \times 12.5 \mathrm{~mm}$ 5-Micron; Narrow-Bore $2.1 \times 150 \mathrm{~mm} 5 \mu \mathrm{m})$. Subsequently, the mixture was loaded with a flow rate of $300 \mu \mathrm{l} / \mathrm{min}$ for $1 \mathrm{~h}$ using a linear binary gradient of $0-80 \%$ buffer B $(350 \mathrm{mmol} / \mathrm{L}$ $\mathrm{KCl}$ in solvent $\mathrm{A}, \mathrm{pH}=2.8$ ). Eventually, a total of 6 SCX fractions were collected per iTRAQ set; and the absorbance at 210 and $280 \mathrm{~nm}$ was monitored.

\section{LC-MS/MS analysis}

The mixed peptides, which were desalted with a PepMap C18 cartridge, were further separated by LC-20AD nano-RPLC (AB SCIEX) on the secondary $\mathrm{RP}$ analytical column $(75 \mu \mathrm{m} \times 15 \mathrm{~cm}$ C18- $3 \mu \mathrm{m} 120 \AA$, ChromXP Eksigent). Peptides were subsequently eluted using the gradient conditions with phase $\mathrm{B}$ at a flow rate of $300 \mu \mathrm{L} / \mathrm{min}$ (5\% phase B for $8 \mathrm{~min}, 25 \%$ phase B for $38 \mathrm{~min}, 40 \%$ phase B for $50 \mathrm{~min}, 90 \%$ phase $B$ for $60 \mathrm{~min}, 2 \%$ phase $B$ for $65 \mathrm{~min}$, and 0 phase B for $70 \mathrm{~min})$. Phase B was composed of $95 \%$ $\mathrm{ACN}$ and $0.1 \%$ formic acid.

Electrospray voltage of $2.5 \mathrm{kV}$ versus the inlet of the mass spectrometer (TripleTOF5600) was used. A hybrid quadrupole time-of-flight mass spectrometer (QStar hybrid LC/MS/MSQ-TOF, AB SCIEX, China) 
was operated in information dependent analysis mode for switching automatically between MS and MS/MS acquisition. MS spectra were acquired across the mass range of $400-1800 \mathrm{~m} / \mathrm{z}$ in high-resolution mode using $250 \mathrm{msec}$ accumulation time per spectrum. For information-dependent acquisition, survey scans were acquired in $250 \mathrm{msec}$-and as many as 35 product ion scans were collected if they exceeded a threshold of 150 counts per second (counts/s) with a $2+$ to $5+$ charge-state. Tandem mass spectral scanned from $100-2000 \mathrm{~m} / \mathrm{z}$ in high-sensitivity mode with collision-induced dissociation. Dynamic exclusion was set for $1 / 2$ of peak width (18s). The precursor was then refreshed off the exclusion list.

\section{Protein identification}

The obtained LC-MS/ MS data were also analyzed by Sangon Biotech (Shanghai) Co., Ltd. Data were analyzed using the SEQUEST algorithm and comparing the results against the findings described in NCBI Human RefSeq database. The search parameters included iTRAQ labeling at N-terminus and lysine residues, cysteine modification by methyl methanethiosulfonate (MMTS), and digestion by trypsin. In our study, the cutoff value $>1.3$ and peptides $>=1$ was applied towards protein identification. Proteins were considered as being differentially expressed if iTRAQ ratios were $\geq 2.0$ or $\leq 0.5$ in the carcinoma tissue group as compared to the pericarcinous tissue group. In addition, the $P$ values $<0.05$ of iTRAQ ratios in at least one of the data sets was considered as being significantly differentially expressed.

\section{Bioinformatics analysis}

The basic properties of the differentially expressed protein database were analyzed with GENENTOLOGY (http://www.pantherdb.org/), DAVID 6.7 (https:// david.ncifcrf.gov/), and STRING (https://string-db.org/).

\section{Tissue microarray (TMA)}

Tissue microarrays (TMAs) were constructed by the Department of Pathology, Basic Medical School of Lanzhou University. In addition, Shanghai Outdo Biotech Company (Shanghai, China) provided technical advice during this process. H\&E-stained section of the TMA recipient block was prepared and reviewed to confirm the presence of intact neoplasm. The TMA contained a total of 122 point, of which 31 included both carcinoma foci and non-carcinoma foci. Every core was obtained from each paraffin-embedded CCA sample (using punch cores measuring $1.9 \mathrm{~mm}$ at their greatest diameter) from the non-necrotic area of carcinoma foci and/or non-carcinoma foci.

\section{Immunohistochemistry (IHC)}

\section{Antibodies}

IHC was performed using the following antibodies, which were all obtained from Abcam ( Shanghai, China). Peroxiredoxin2 (PRDX2) was detected by Rabbit monoclonal Anti-Peroxiredoxin2 (ab109367). Biglycan (BGN) was detected by rabbit polyclonal Anti-Biglycan (ab49701). Lumican (LUM) was detected by rabbit monoclonal Anti-Lumican (ab168348). PPP3CA expression was examined by rabbit polyclonal Anti-Calcineurin A antibody (ab71149). SP-9001 SPlink Detection Kit (Biotin-Streptavidin HRP Detection Systems), 3,3' diaminobenzidine (DAB) Chromogen/HRP Substrate kit, and avidin-biotinylated horseradish peroxidase complex $(\mathrm{ABC})$ were purchased from Zhongshan Golden Bridge Biotechnology Co. (Beijing, China).

\section{Staining Procedure}

IHC staining was performed on formalin fixed paraffin embedded tissue sections $(3 \mu \mathrm{m})$ and TMAs by an immunoperoxidase method using the avidin-biotinylated horseradish peroxidase (ABC) complex. Each section was deparaffinized with xylene and rehydrated in descending dilutions of ethanol and distilled water, respectively. Antigen retrieval was performed by the immersion of tissue sections and TMAs in pre-heated $10 \mathrm{mM}$ citrate buffer solution $(\mathrm{pH} 6.0)$ and maintaining heat at $120^{\circ} \mathrm{Cin}$ a pressure cooker for $3 \mathrm{~min}$. Endogenous peroxidase was blocked by incubating the sections in $0.3 \%$ hydrogen peroxidase at room temperature for $10 \mathrm{~min}$. The sections and TMAs were washed in $0.01 \mathrm{~mol} / \mathrm{L}$ phosphate-buffered saline (PBS, pH 7.4). $\%$ normal goat serum in PBS was applied for $10 \mathrm{~min}$ at room temperature to prevent non-specific staining.

In the staining using each antibody, the sections and TMAs were incubated with dilutions of the primary antibodies (PRDX2, 1:300; BGN, 1:100; LUM, 1:20; PPP3CA, 1:100) in PBS at $4^{\circ} \mathrm{C}$ overnight. The sections were washed 3 times with PBS and incubated with the biotinylated secondary antibodies, and then were washed 3 times with PBS. All the sections then received $\mathrm{ABC}$ complex for $20 \mathrm{~min}$ at $37^{\circ} \mathrm{C}$. After washing with PBS 3 times, the sections were finally reacted with $\mathrm{DAB}$ substrate for $10 \mathrm{~min}$ for visualization, rinsed with tap water, counterstained with hematoxylin, and mounted.

\section{Evaluation of the Results by Scoring}

Immunoreactivity was evaluated independently by two pathologists who were blinded to the research design. Any discrepant scores were re-examined by 
both pathologists to reach a consensus score. Expression of PRDX2 in the cytoplasm was evaluated. In BGN, the cytoplasm and/or nucleus was evaluated. In LUM, membranous and cytoplasm was evaluated. For PPP3CA expression in cytoplasm was evaluated. A total immunostaining score (TIS) was calculated as the product of a percentage score and an intensity score as previously described [15]. The percentage score described the estimated percentage of positively stained neoplastic cells $(0: 0-5 \%$; 1 : 6-25\%; 2: $26-50 \%$; 3: $51-75 \%$; $4:>75 \%)$. The intensity score represented the estimated staining intensity (0: no or marginal staining; 1 : weak; 2: moderate; 3 : strong). The TIS ranged from 0 to 12 . We defined 0 as negative, 1-4 as weak positive, 5-8 as moderate positive, and 9-12 as strong positive.

\section{Statistical analysis}

Statistical analysis was performed using the chi-square test, Fisher exact test, or $t$-test where appropriate. The overall survival (OS) of CCA patients was compared between the group with PPP3CA expression and the non-expressing group by using the Kaplan-Meier method; and differences between the survival curves were tested using the log-rank test. Univariate and multivariate survival analyses were performed using the Cox proportional hazards regression model. For the multivariate model, we used 0.10 as the cutoff $P$-value to select the analyzed factors from the univariate analysis data. A probability of a $P$ less than 0.05 was considered to be statistically significant. All statistical analyses were conducted with the SPSS 17.0 software package (SPSS Inc., Chicago, IL).

\section{Results}

\section{Proteins differentially expressed between primary CCA and pericarcinous tissue}

Among the 6 paired primary CCA and pericarcinous tissue, we identified 2,886 confidential proteins with a confidence interval $(\mathrm{CI}) \geq 95 \%$ by using the iTRAQ technique. Among these, 233 proteins were differentially expressed in CCA tissue and pericarcinous tissue, which including 99 up-regulated and 134 down-regulated proteins. Supplementary Figure 1 shows the chromatographic separation of small molecules in CCA tissue. And a cluster heatmap (Supplementary Figure 2) was applied to visualize the gene expression data in CCA, which shows the up-regulated (red color) and down-regulated proteins (green color). Moreover, as Fig. 1a shows, these proteins can be classified into seven categories for cellular components using the PANTHER classification system. A majority of proteins identified were classified as being a cell part
$(31.78 \%)$, organelle $(23.36 \%)$, from the extracellular region $(22.43 \%)$, or cytoplasmic $(26.90 \%)$ in nature. Other identified proteins were classified as originating in the macromolecular complex (12.15\%), the extracellular matrix (4.67\%), membranes $(4.67 \%)$, and synapses $(0.93 \%)$. GENEONTOLOGY analysis revealed that the pathways associated with these proteins can be classified into 28 groups. As shown in Fig. $\mathbf{1 b}$, the top 5 five pathway groups were blood coagulation $(16.44 \%)$, the integrin signaling pathway $(12.33 \%)$, inflammation mediated by the chemokine and cytokine signaling pathway $(9.59 \%)$, cytoskeletal regulation by Rho GTPase $(8.22 \%)$, and either the CCKR signaling map $(5.48 \%)$ or plasminogen activating cascade $(5.48 \%)$.

In addition, functional annotation analysis showed that these proteins could be divided into 66 functional groups. The top ten functional groups consisted of the following: protein binding (68.3\%), poly(A) RNA binding (35\%), calcium ion binding $(22 \%)$, identical protein binding (22\%), heparin binding (19\%), structural molecule activity (16\%), serine-type endopeptidase inhibitor activity (13\%), extracellular matrix structural constituent (12\%), cadherin binding involved in cell-cell adhesion (12\%), and structural constituent of cytoskeleton (11\%) (Fig. 1c). Based on the functional process of differentially expressed proteins and Venn diagram results (Fig. 1d, 1e) which showed the intersections of differentially expressed proteins among different paired groups, we selected 18 significantly differentially expressed proteins. These are summarized in Table 3.

By searching STRING (https://string-db.org/), as Fig. 1f shows, we found the STRING interaction network of these 18 proteins. By means of literature review, we found that MUC1, MUC5AC, EGFR, TGFB1, and TNF, etc., have been demonstrated with prognostic and/or diagnostic value in relation to CCA $[16,17]$. Finally, based on the functional process of the remaining proteins, we selected PRDX2, BGN, LUM, and PPP3CA as potential biomarkers for further examination of the in-tissue expression profile. In addition, by searching the online TCGA database (https://cancergenome.nih.gov/), we performed additional analyses of the expression of LUM, PRDX2, BGN, and PPP3CA in CCA based on the patient's race, which were depicted in Fig. 2, and the statistical significance for the comparison of the expression of LUM, PRDX2, BGN, and PPP3CA based on the patient's race is summarized in Supplementary table 1.

\section{Hematoxylin and eosin (H\&E) staining}

Fig. 3a and Fig. 3A showed the H\&E-stained sections of choledochal cyst and CCA, respectively. 
Table 3. The Basic Properties of Selected Protein Screened from Proteomics

\begin{tabular}{|c|c|c|c|c|}
\hline Accession No. & Gene symbol & Sequence coverage $(\%)$ & Peptides & Gene ID \\
\hline sp|P51884|LUM_HUMAN & LUM & 57.1 & 62 & 4060 \\
\hline sp|Q07812|BAX_HUMAN & BAX & 32.3 & 3 & 581 \\
\hline sp | P98088|MUC5A_HUMAN & MUC5AC & 2.7 & 2 & 4586 \\
\hline tr|A0A0C4DGW3_HUMAN & MUC1 & 8.2 & 3 & 4582 \\
\hline sp|P21810|PGS1_HUMAN & BGN & 63.3 & 64 & 633 \\
\hline sp |P07585|PGS2_HUMAN & $\mathrm{DCN}$ & 28 & 69 & 1634 \\
\hline sp|Q9BXN1|ASPN_HUMAN & ASPN & 59 & 36 & 54829 \\
\hline sp|P17612|KAPCA_HUMAN & PRKACA & 13.1 & 3 & 5566 \\
\hline sp|Q08209|PP2BA_HUMAN & РРР3СА & 20.4 & 8 & 5530 \\
\hline sp|P00533 | EGFR_HUMAN & EGFR & 3.5 & 2 & 1956 \\
\hline sp|P32119|PRDX2_HUMAN & PRDX2 & 75.3 & 47 & 7001 \\
\hline sp |Q06830|PRDX1_HUMAN & PRDX1 & 62.3 & 24 & 5052 \\
\hline sp|O43294|TGFI1_HUMAN & TGFB1 & 18.9 & 8 & 7040 \\
\hline sp | P28799|GRN_HUMAN & GRN & 15 & 8 & 2896 \\
\hline sp |Q03169|TNAP2_HUMAN & TNF & 18.2 & 5 & 7124 \\
\hline sp|P60709|ACTB_HUMAN & АСТВ & 88.5 & 490 & 60 \\
\hline tr|H0Y7A7|H0Y7A7_HUMAN & CALM2 & 57.2 & 28 & 805 \\
\hline sp | P16298 | PP2BB_HUMAN & РPР3СВ & 20.6 & 6 & 5532 \\
\hline
\end{tabular}

a
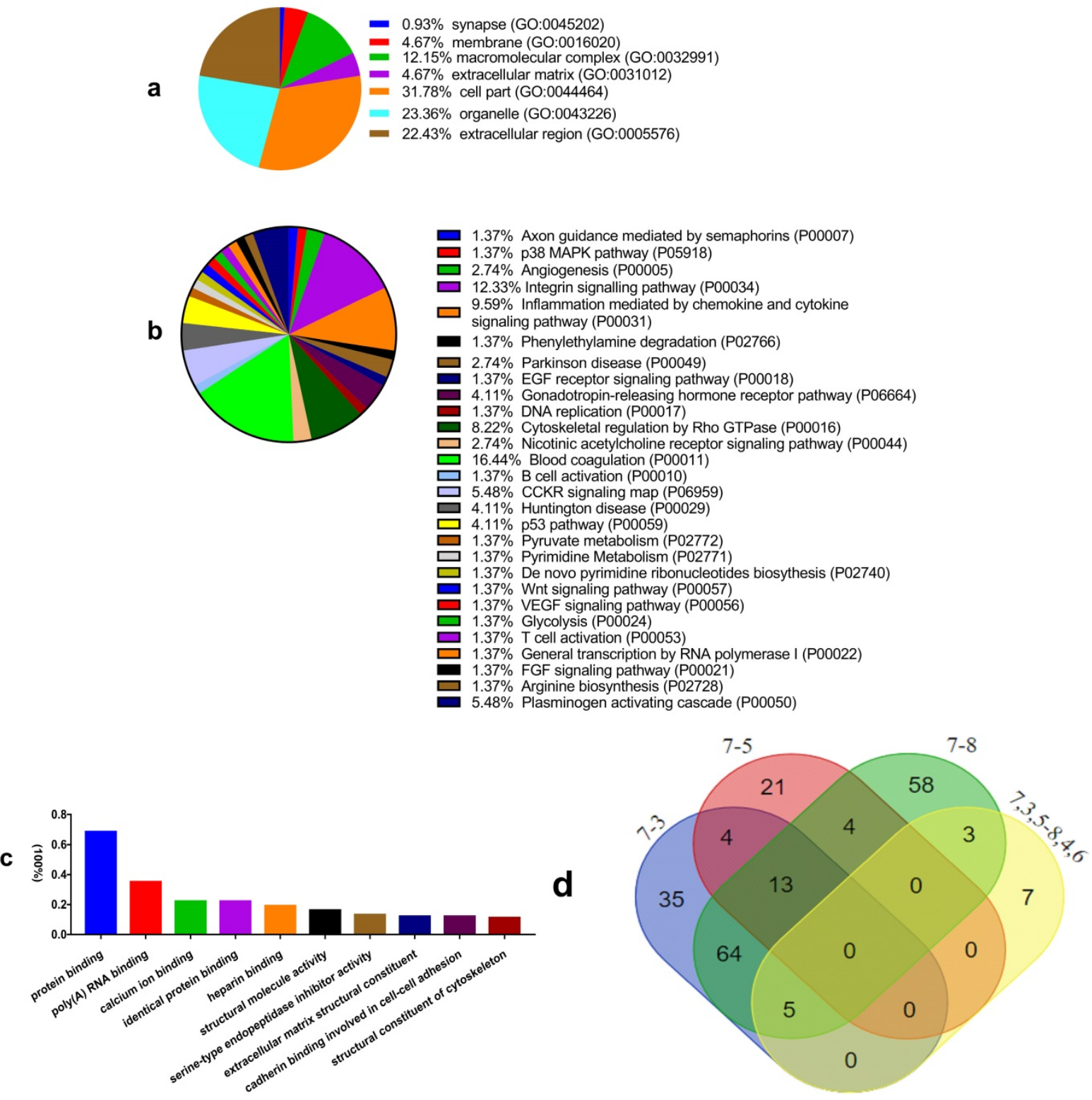

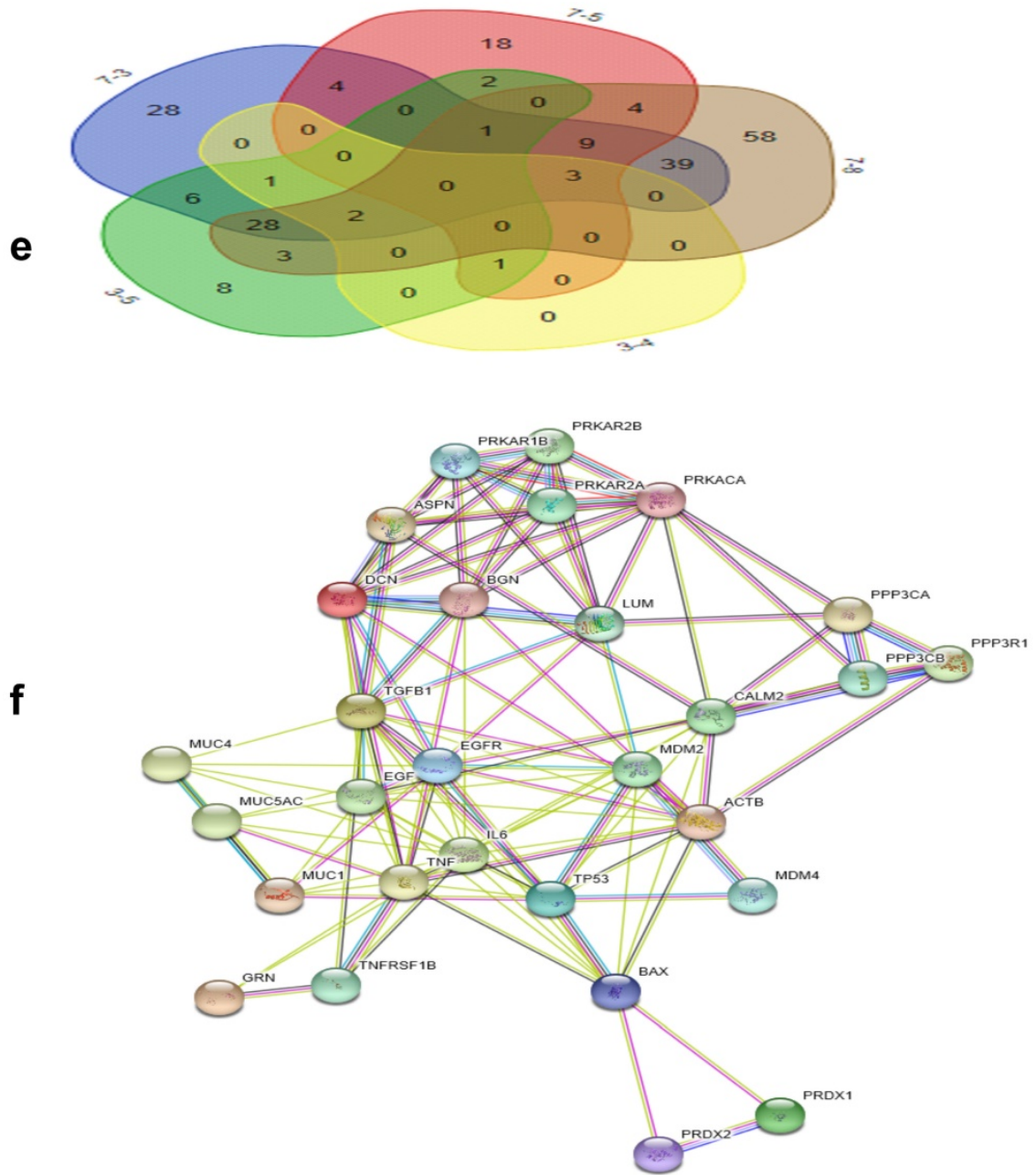

Figure 1. GO analysis of the differentially expressed proteins: The cellular component distribution of identified proteins (a); The pathways of these proteins involvement (b). The top ten biological processes enriched by DAVID (c). Venn diagram showing the intersections of identified proteins in different groups (d, e). The functional network of 19 differentially expressed proteins by searching in the STRING Database (f).

\section{PRDX2, LUM, BGN, or PPP3CA expression in choledochal cysts}

PRDX2 was not expressed in choledochal cysts (Fig. 3b). BGN was lowly expressed in the cell cytoplasm in $1(20 \%)$ of 5 of choledochal cysts tissues (Fig. 3c). LUM was expressed in the cell membrane and cytoplasm in $3(60 \%)$ of 5 of choledochal cyst tissues (Fig. 3d); and PPP3CA was not expressed in choledochal cyst tissue (Fig. 3e).

\section{PRDX2, LUM, BGN, or PPP3CA expression in CCA}

PRDX2 was in the cytoplasm of carcinoma cells in all 5 CCA cases (Fig. 2B). BGN was expressed in the cytoplasm and/or nucleus of carcinoma cells in 2 $(40 \%)$ of 5 CCA cases (Fig. 3C). LUM was expressed in the cell membrane and cytoplasm of carcinoma cells $3(60 \%)$ of 5 CCA cases (Fig. 3D). PPP3CA was seen in the cytoplasm of carcinoma cells in 22(24.2\%) of 91 CCA in TMA (Fig. 3E, 3F). The overall staining profile of PPP3CA expression in TMA is shown in Fig. 3G.

\section{The semi-quantitative analysis of the expression of PRDX2, BGN, LUM, and PPP3CA in CCA tissue and choledocal cyst tissue}

As Fig. 4 shows, the expression of PRDX2, BGN, and PPP3CA was significantly lower in choledocal cyst tissue than in CCA tissue $(P<0.001)$. Furthermore, in LUM, there was also a significant difference between CCA tissue and choledocal tissue $(P=0.004)$.

\section{Relationship between PPP3CA expression and clinicopathological features of CCA patients}

In the analysis of the PPP3CA expression and of clinicopathological features, 3 patients were excluded since these patients were lost during follow-up. PPP3CA expression was not related to most of the clinicopathological features included in Table 4. 
Table 4. Summary of The Data on The Expression of PPP3CA in Clinicopathological Features of 88 Cases of CCA

\begin{tabular}{|c|c|c|c|c|}
\hline \multirow[t]{2}{*}{ Category } & \multirow[t]{2}{*}{ No. Patients (\%) } & \multicolumn{2}{|l|}{ PPP3СA(\%) } & \multirow[t]{2}{*}{ P value } \\
\hline & & Positive $(\geq 1+)$ & Negative (0) & \\
\hline \multicolumn{5}{|l|}{ Gender } \\
\hline Male & $45(51.1)$ & $11(24.4)$ & $34(75.6)$ & 0.902 \\
\hline Female & $43(48.9)$ & $11(25.6)$ & $32(76.4)$ & \\
\hline \multicolumn{5}{|l|}{ Age (yrs) } \\
\hline$>55$ & $50(56.8)$ & $14(63.6)$ & $36(54.5)$ & 0.456 \\
\hline$\leq 55$ & $38(43.2)$ & $8(36.4)$ & $30(45.5)$ & \\
\hline \multicolumn{5}{|c|}{ T-stage (AJCC7th) } \\
\hline $\mathrm{T} 1,2$ & $67(76.1)$ & 17(77.3) & $50(75.8)$ & 0.885 \\
\hline $\mathrm{T} 3,4$ & $21(23.9)$ & $5(22.7)$ & $16(24.2)$ & \\
\hline \multicolumn{5}{|c|}{ Lymph node metastasis } \\
\hline N0 & $58(65.9)$ & $11(50.0)$ & $47(71.2)$ & 0.069 \\
\hline N1 & $30(34.1)$ & $11(50.0)$ & $19(28.8)$ & \\
\hline \multicolumn{5}{|c|}{ Vascular invasion } \\
\hline Negative & $29(33.0)$ & $15(68.2)$ & $44(66.7)$ & 0.896 \\
\hline Positive & $59(67.0)$ & $7(31.8)$ & $22(33.3)$ & \\
\hline \multicolumn{5}{|c|}{ Tumor size (cm) } \\
\hline$>3.5$ & $31(35.2)$ & $11(50.0)$ & $20(30.3)$ & 0.094 \\
\hline$\leq 3.5$ & $57(64.8)$ & $11(50.0)$ & $46(69.7)$ & \\
\hline \multicolumn{5}{|c|}{ Histological grading } \\
\hline Poorly & 12(13.6) & $3(13.6)$ & $9(13.6)$ & 0.269 \\
\hline Moderate & $68(77.3)$ & $15(68.2)$ & $53(80.3)$ & \\
\hline Well & $8(9.1)$ & $4(18.2)$ & $4(6.1)$ & \\
\hline
\end{tabular}

\begin{tabular}{lllll}
\hline Category & No. Patients (\%) & \multicolumn{2}{l}{ PPP3CA(\%) } & P value \\
\cline { 3 - 4 } & & Positive $(\geq \mathbf{1 + )}$ & Negative (0) & \\
\hline Survival (mo.) & & $7(31.8)$ & $34(51.5)$ & 0.109 \\
$>12$ & $41(46.6)$ & $15(68.2)$ & $32(48.5)$ & \\
$\leq 12$ & $47(53.4)$ & & \\
\hline
\end{tabular}

\section{Relationship between PPP3CA expression and overall survival rate}

Among the 88 patients examined, 52 patients died during the follow-up period. Median and mean length of survival for CCA who underwent surgery therapy was 14.9 and 24.4 months, respectively. The 1 and 3-year OS rates for patients with positive PPP3CA expression were $33 \%$ and $19 \%$, respectively. The 1 and 3-year OS rates for patients with PPP3CA negative expression were $65 \%$ and $32 \%$, respectively. The survival rate of patients with PPP3CA positive expression $(n=22)$ was significantly poorer than for those with PPP3CA negative expression $(n=66)(P=$ 0.030, log-rank test; Fig. 5).

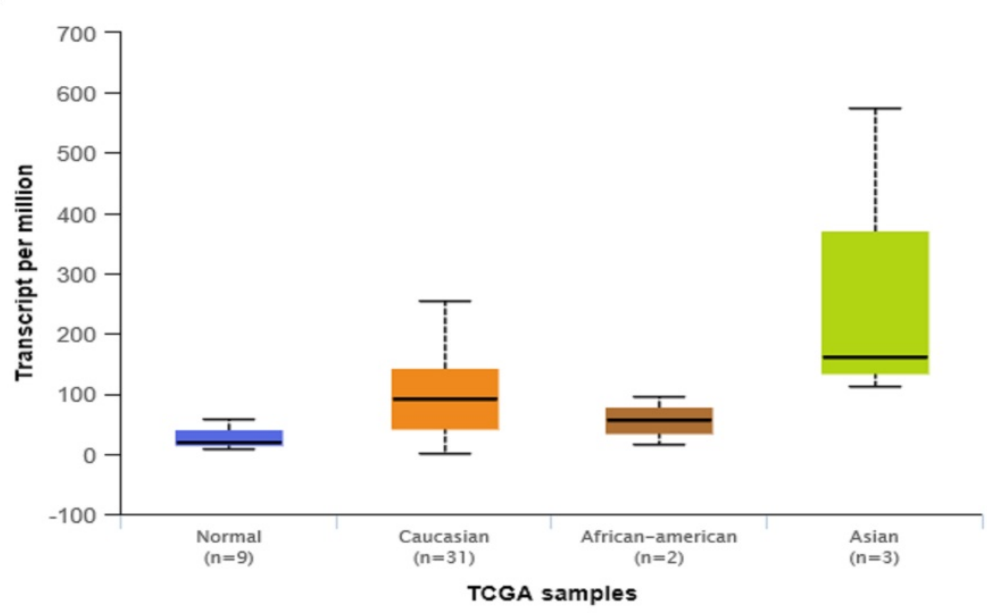

b Expression of PRDX2 in CHOL based on patient's race $\equiv$

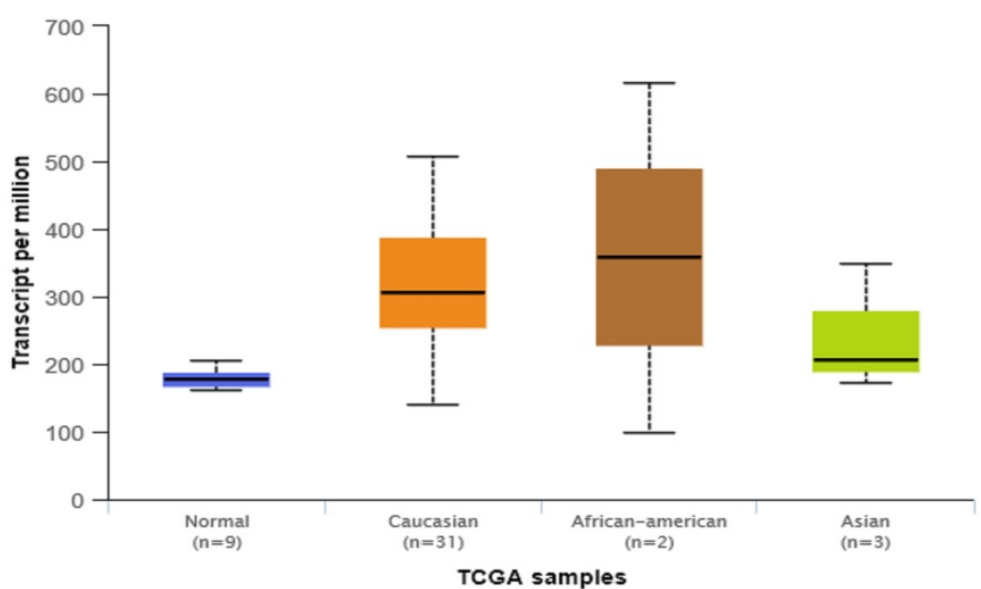



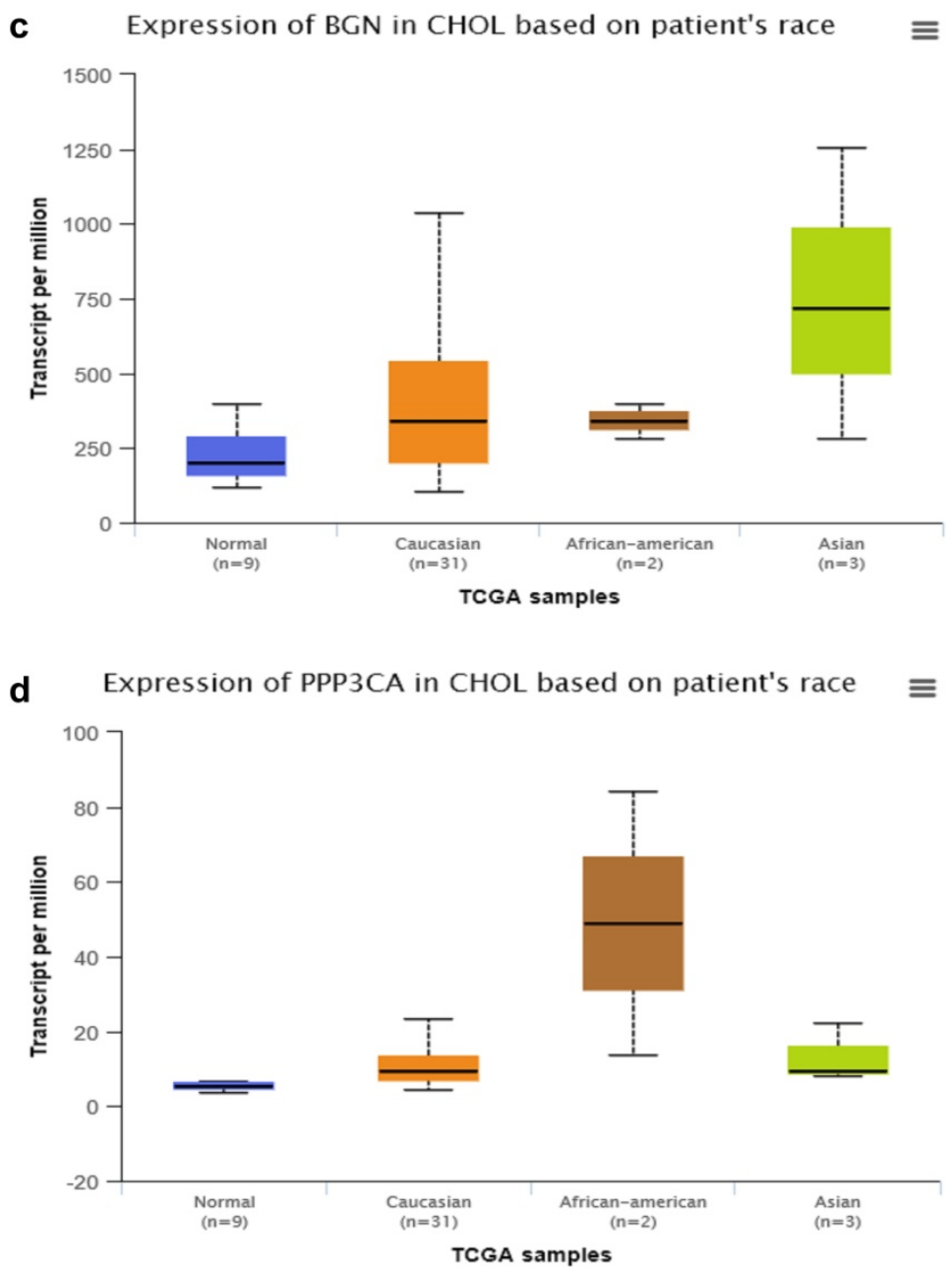

Figure 2. The comparison of expression of LUM (a), PRDX2 (b), BGN (c), and PPP3CA (d) in CCA based on the patient's race by searching the online TCGA database.

Table 5a. Univariate Analysis of Prognostic Factors

\begin{tabular}{|c|c|c|c|}
\hline Variable & Hazard ratio & 95\%confidence interval & P value \\
\hline \multicolumn{4}{|l|}{ Gender } \\
\hline Male ( $\mathrm{n}=45)$ & 1 & & \\
\hline Female $(n=43)$ & 0.801 & $0.460-1.398$ & 0.435 \\
\hline \multicolumn{4}{|l|}{ Age (yrs) } \\
\hline$\leq 55(\mathrm{n}=38)$ & 1 & & \\
\hline$>55(\mathrm{n}=50)$ & 1.007 & $0.566-1.791$ & 0.981 \\
\hline \multicolumn{4}{|l|}{ T-stage (AJCC7th) } \\
\hline $\mathrm{T} 1,2(\mathrm{n}=67)$ & 1 & & \\
\hline $\mathrm{T} 3,4(\mathrm{n}=21)$ & 1.547 & $0.862-2.776$ & 0.143 \\
\hline \multicolumn{4}{|c|}{ Lymph node metastasis } \\
\hline $\mathrm{N} 1(\mathrm{n}=30)$ & 1 & & \\
\hline N0 (n = 58) & 0.604 & $0.343-1.064$ & 0.081 \\
\hline \multicolumn{4}{|l|}{ Vascular invasion } \\
\hline Negative $(n=29)$ & 1 & & \\
\hline Positive $(\mathrm{n}=59)$ & 2.631 & $1.511-4.580$ & $0.001^{* *}$ \\
\hline \multicolumn{4}{|l|}{ Tumor size (cm) } \\
\hline$\leq 3.5(\mathrm{n}=57)$ & 1 & & \\
\hline$>3.5(\mathrm{n}=31)$ & 2.435 & $1.384-4.284$ & $0.002^{* *}$ \\
\hline \multicolumn{4}{|c|}{ Histological grading } \\
\hline Poorly (12) & 1 & & \\
\hline Moderate (68) & 0.162 & $0.040-0.655$ & $0.011^{*}$ \\
\hline Well (8) & 0.473 & $0.199-1.120$ & 0.089 \\
\hline \multicolumn{4}{|l|}{ PPP3CA } \\
\hline Negative (66) & 1 & & \\
\hline Positive(22) & 1.906 & $1.052-3.454$ & $0.033^{*}$ \\
\hline
\end{tabular}

\section{Univariate and multivariate analysis of prognostic factors}

The univariate analysis of prognostic factors of CCA is summarized in Table 5a. Tumor size $(P=$ 0.002), vascular invasion $(P=0.001)$, histological grading $(P=0.011)$, and PPP3CA expression $(P=$ 0.033 ) were statistically significant risk factors affecting the outcomes of CCA patients. In multivariate analysis, as summarized in Table 5b, vascular invasion $(P=0.012)$ and PPP3CA expression $(P=0.009)$ were found to be statistically significant independent risk factors for the OS of CCA patients.

\section{Discussion}

Surgical resection with histologically negative resection margins and/or liver transplantation was the only effective treatment option for CCA patients with a long survival rate, whereas chemotherapies were widely reported to remain poorly characterized and virtually palliative given the marked chemoresistance of this heterogeneity group of cancer $[17,18]$. Currently, there are few biomarkers with high 
diagnostic and/or prognostic capability for detecting CCAs or for predicting the prognosis of CCA patients.

Table 5b. Multivariate Analysis of Prognostic Factors

\begin{tabular}{llll}
\hline Variable & Hazard ratio & 95\%confidence interval & P value \\
\hline $\begin{array}{l}\text { Vascular invasion } \\
\text { Negative }(\mathrm{n}=29)\end{array}$ & 1 & & \\
$\begin{array}{l}\text { Positive }(\mathrm{n}=59) \\
\text { Tumor size }(\mathrm{cm})\end{array}$ & 2.204 & $1.191-4.079$ & $0.012^{*}$ \\
$\leq 3.5(\mathrm{n}=57)$ & 1 & & \\
$>3.5(\mathrm{n}=31)$ & 1.694 & $0.914-3.139$ & 0.094 \\
$\begin{array}{l}\text { Histological grading } \\
\text { Well/Moderate }\end{array}$ & 1 & & \\
$\begin{array}{l}\text { Poorly } \\
\text { PPP3CA }\end{array}$ & 2.664 & $0.806-8.808$ & 0.108 \\
Negative & 1 & & \\
positive & 2.279 & $1.228-4.229$ & $0.009^{* *}$ \\
\hline$* P<0.05 ; * * P<0.01$ & & &
\end{tabular}

In our study, we used the iTRAQ proteomic technique to find the differentially expressed proteins between the matched CCA and pericarcinous tissue.
233 differentially expressed proteins were identified in the initial search. Compared with pericarcinous tissues, 99 proteins were up-regulated and 134 proteins were down-regulated in CCA cases. Most of these proteins were involved in blood coagulation $(16.44 \%)$, the integrin signaling pathway (12.33\%), inflammation mediated by the chemokine and cytokine signaling pathway $(9.59 \%)$, cytoskeletal regulation by Rho GTPase $(8.22 \%)$, and the CCKR signaling map (5.48\%), etc. Based on the results of the bioinformatic analysis and the literature review, we selected PRDX2, BGN, LUM, and PPP3CA as novel candidate biomarkers of CCA, as the expression profiles of these proteins in CCA were rarely reported. We further examined the expression profile of the selected biomarker in CCA tissue samples by using IHC. In addition, we assessed the PPP3CA expression rate in a total of 91 CCA cases and investigated the prognostic role of PPP3CA in CCA patients.
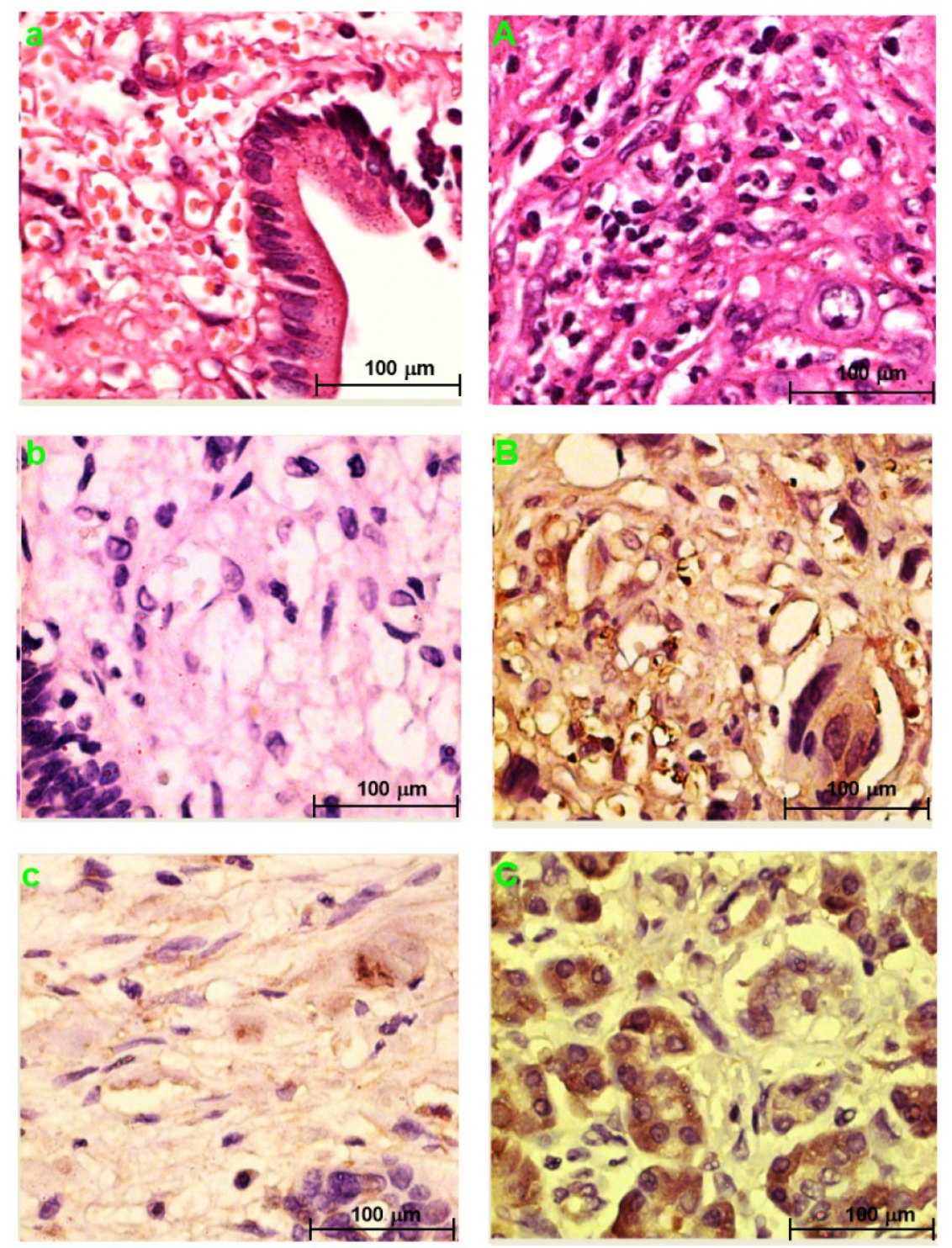

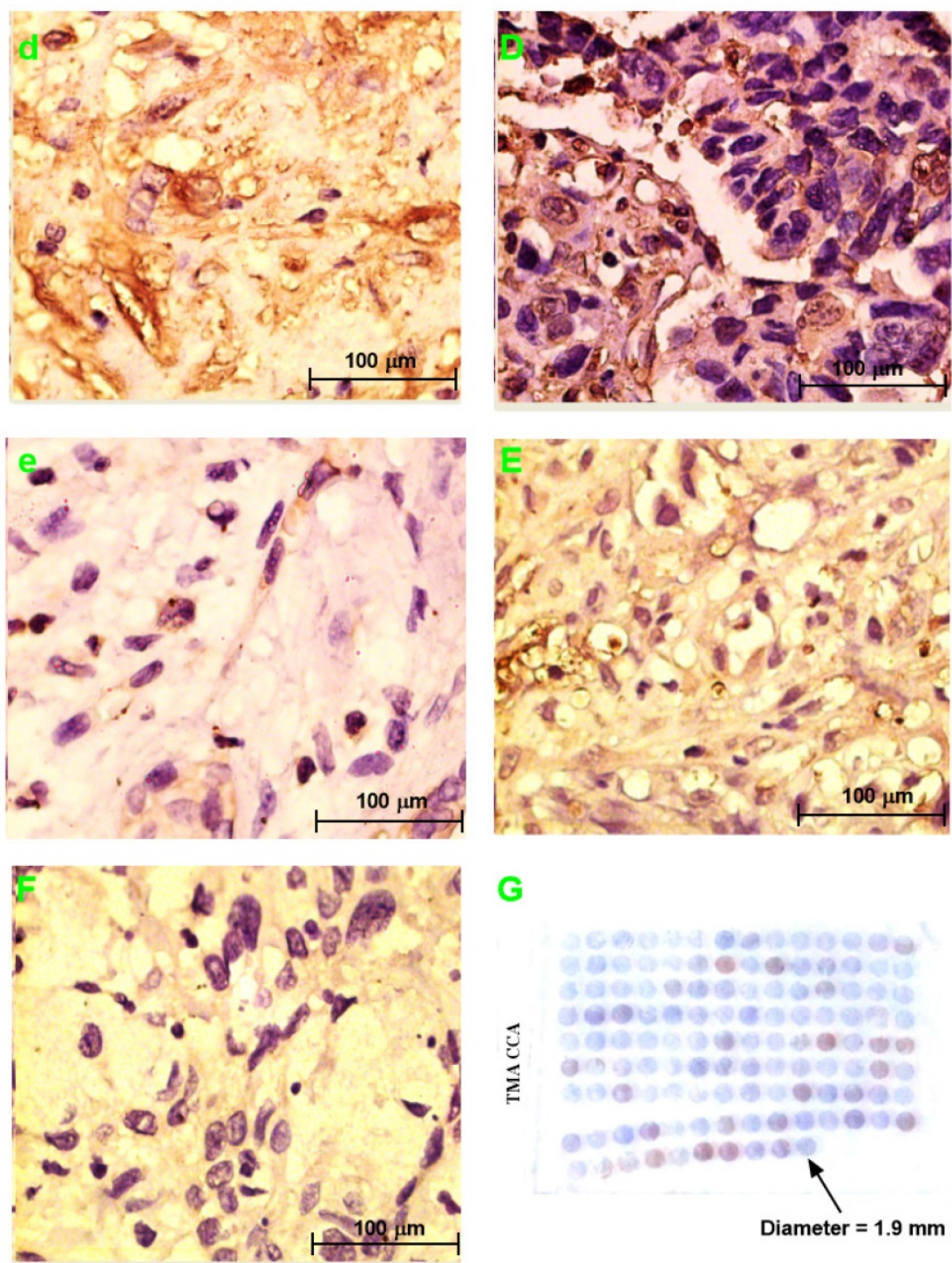

Figure 3. H\&E staining section of choledochal cyst (a); H\&E staining section of CCA (A). Original magnification $\times 200$ (a, A). IHC staining section of the choledochal cyst: PRDX2 (b) and PPP3CA (e) are not expressed, whereas BGN lowly expressed in the cytoplasm (c), and LUM is expressed in the cell membrane and the cytoplasm (d). IHC staining section of the carcinoma: PRDX2 is expressed in the cytoplasm (B), while BGN is expressed in the cytoplasm and/or the nucleus (C). LUM is expressed in both the cell membrane and the cytoplasm (D). PPP3CA was highly expressed in cytoplasm (E) and lowly expressed in cytoplasm (F). Original magnification $\times 200(\mathbf{a}-\mathbf{e} ; \mathbf{A}-\mathbf{F})$. The overall staining profile of PPP3CA expression in TMAs $(\mathbf{G})$.

PRDX-2, a typical 2-Cys thioredoxin peroxidase and a cellular antioxidant, which have been considered as being a tumor-suppressing protein with the feature of regulating levels of hydrogen peroxide and mediating several signal transduction pathways which are linked to the regulation of cell proliferation, differentiation, and apoptosis [19-21]. In our study, we firstly found that the expression pattern of PRDX-2 in CCA was down-regulated as compared with that in pericarcineous samples using iTRAQ-based quantitative proteomic analysis. In addition, as with the increased expression of PRDX2 in colorectal cancers, B cell-derived primary lymphoma cells, and cervical cancer, etc. [22], similarly, we firstly found that PRDX-2 was positively expressed CCA cases but not expressed in choledochal cyst tissues, that is, the expression profile of PRDX2 in CCA is increased as compared with its expression in choledochal cyst tissues. However, the expression profile of PRDX2 in carcinomas is not always increased, given that a decreased expression of PRDX2 in melanomas has been demonstrated [23]. PRDX2 can show a tumor-promoting effect or tumor-suppressive function based on tumor type. Further study needs to be performed to elucidate the mechanism of PRDX2 in the development CCA.

BGN, a classical type of extracellular matrix protein, is normally secreted from extracellular matrix fibroblasts, and facilitates the assembly of collagen fibrils and the bone matrix [24]. The increased expression of BGN induces the activation of the NF-кB pathway via TLR2/4 signaling. The activation 
of NF-кB is associated with the aggressive growth of tumors and contributes to the resistance to chemotherapies during cancer treatments [25,26]. Moreover, BGN up-regulation has been demonstrated in many malignancies such as pancreatic adenocarcinoma [27], prostate cancer [28], and colon cancers [24], etc. In addition, Nishino et al. [29] previously reported that $\mathrm{BGN}$ has the capacity of differentiating intrahepatic CCA from hepatocarcinoma or metastatic adenocarcinoma. In our study, we firstly found that the expression profile of BGN in extrahepatic cholangiocarcinoma was increased as compared with its expression in choledocal cysts. CCA classified as intrahepatic CCA, perihilar CCA, and distal CCA based on its anatomical location-which is associated with significant inter-tumor and intra-tumor differences that can affect pathogenesis and therapeutic outcome. The function of BGN in the development of CCA is still unclear. Future studies need to enucleate the molecular function of BGN in the development CCA, particularly based on the classification of CCA.

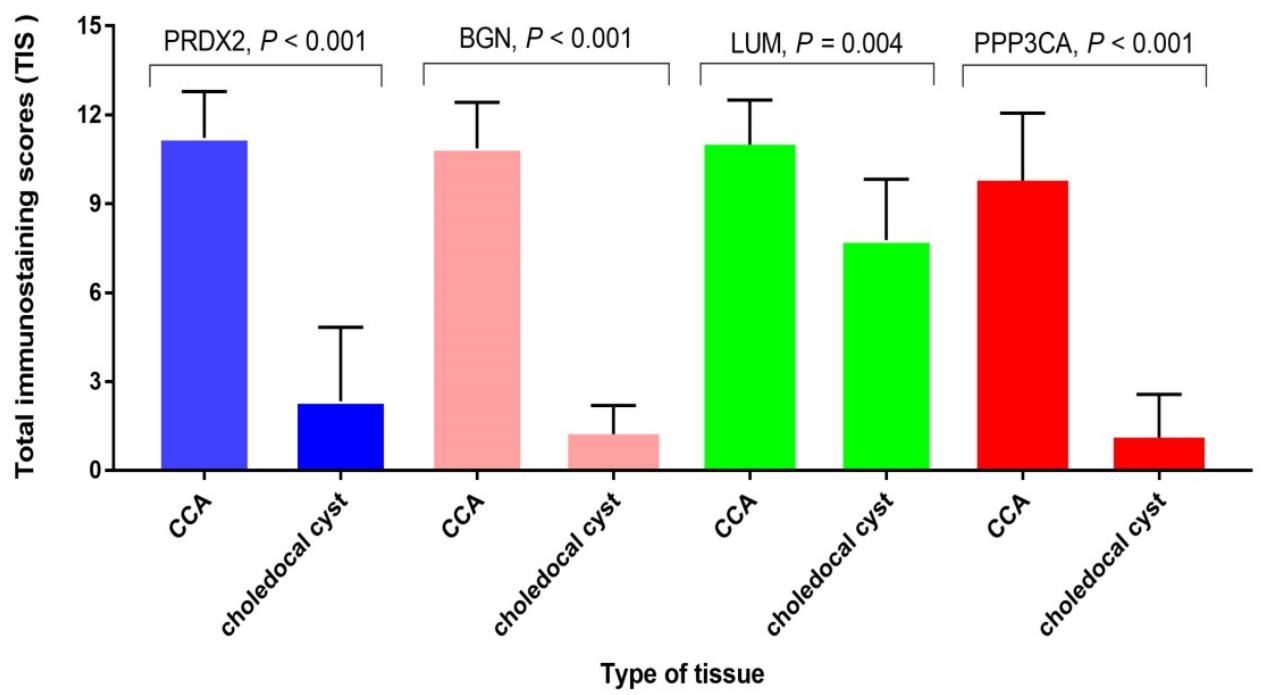

Figure 4. The semi-quantitative analysis of the expression of PRDX2, BGN, LUM, and PPP3CA in CCA tissue and choledocal csyt tissue.

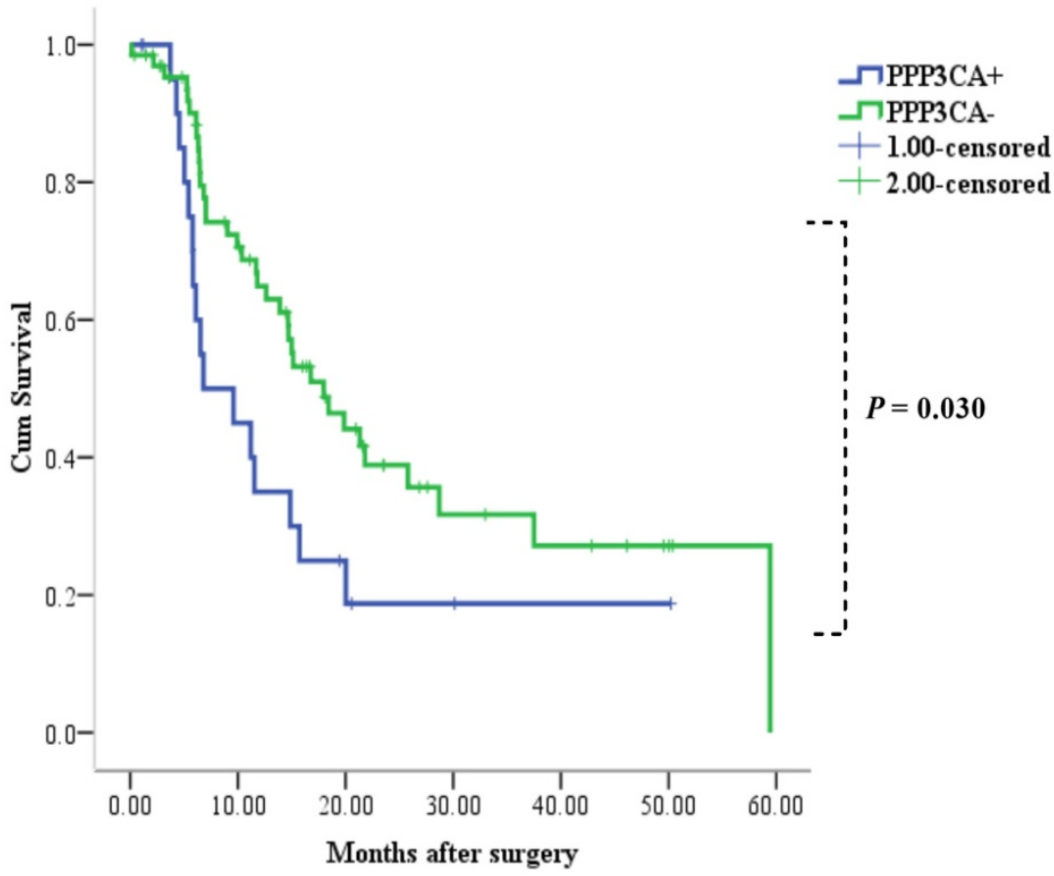

Figure 5. Correlation between PPP3CA expression and cumulative survival rate in patients with CCA (Kaplan-Meier method). The survival rate of patients with PPP3CA positive was poorer than that of patients with PPP3CA negative. 
LUM, a Class II mall leucine-rich proteoglycans, is a key regulator of the organization of tumor matrix and cancer cell-matrix interactions due to its effects on collagen fibrillogenesis and degradation, which binds to cell membrane integrins and receptors and eventually result in the modulation of downstream signaling pathways [30]. The expression of LUM in colorectal cancer [31] and pancreatic cancer [32] has been correlated with poor outcomes in both, Recently, Chen et al. reported that LUM could serve as an independent prognosticative factor in the prediction of gastric cancer [33]. Currently no published reports have focused on investigating the correlation between LUM and CCA. In the present study, iTRAQ-based quantitative proteomic analysis suggested that the expression pattern of LUM in CCA is down-regulated as compared with its expression in pericarcinous tissue; we further found that the expression profile of LUM in CCA tissue was higher than its expression in choledocal cyst tissue (Fig. 4). The function of the increased expression of LUM in the prognosis of CCA, is unclear since the role of LUM in carcinomas can show differences based on the type of tumor involved.

PPP3CA, also known as calcineurin A, a catalytic subunit of calcineurin, contains one catalytic domain and three regulatory domains (including calcineurin B binding, calmodulin binding, and auto-inhibitory domains) [34]. It is encoded by the PPP3CA gene located on chromosome 4q24, and it is responsible for the interaction of calcineurin with $\mathrm{Ca}^{2+} /$ calmodulin [35,36]. Overexpression of the calcineurin family of secretory integrin-binding proteins has been demonstrated to have a correlation with tumor cell adhesion, proliferation, invasion and migration [37 ,38]. Furthermore, PPP3CA expression has been reported to be elevated in breast cancer [39], lung cancer [40], and prostate cancer [41].

In our study, we firstly found that the expression of PPP3CA in CCA tissue was up-regulated as compared with its expression in paired pericarcinous tissue by using the iTRAQ proteomic technique. Further, using the Kaplan-Meier analysis (Fig. 5), we found that PPP3CA expression was significantly related to poor survival of the CCA patients, and that the PPP3CA expression is a statistically significant, independent, poor prognostic factor for CCA patients. That is, the outcomes after surgery were significantly poorer in the patients with PPP3CA-positive expression than in those with PPP3CA-negative expression. Tumor-negative resection margins (histologically); the absence of vascular invasion and the presence of lymph node metastasis; MUC1-negative expression, etc., have been reported as being prognostic factors in patients with resectable
CCA $[4,11,17]$. In our study, the univariate analysis for prognostic factors showed that tumor size, vascular invasion, histological grading, and PPP3CA expression were significant prognostic factors; whereas, in the multivariate analysis, PPP3CA expression, as well as vascular invasion, were independent risk factors for poor prognosis of this intractable disease.

PPP3CA, a protein-encoding gene, has been correlated with tumor development such as pancreatic carcinoma and breast cancer by partaking in the Wnt signaling pathway [39,42]. In addition, in breast cancers, over-expression of PPP3CA in MCF-7 human breast cancer cells has been shown to up-regulate MAPK and NFkB signaling-promoting cell survival and chemoresistance [43], as well as promoting cell growth, migration, and angiogenesis in vivo [44]. Tumor-associated macrophages activate the canonical Wnt- $\beta$-catenin pathway in tumor cells and thereby participate in CCA development by means of the production of Wnt ligands (Wnt3a and Wnt7b) [45]. The depletion of tumor-associated macrophages or the inhibition of Wnt signaling with Wnt inhibitors both in vitro and in mouse and rat CCA models significantly reduced CCA proliferation and increased apoptosis, therby resulting in tumour regression [46]. Furthermore, the MAPK pathway activated by IL-6, which is constitutively secreted by CCA cells - has been correlated with cholangiocyte growth [47]. The exact regulatory mechanisms of PPP3CA in CCA is unclear but may be due to 'parking' in the Wnt signaling pathway and/or MAPK pathway.

In conclusion, we found that PPP3CA, PRDX2, $\mathrm{BGN}$, and LUM were differentially expressed in CCA tissue as compared with their expression in pericarcinous tissue. Expression of PPP3CA in CCA is an independent poor prognostic factor and is a useful marker for predicting the outcomes of CCA patients with surgical resection.

Due to the limitation of funding sources, we only assessed the prognostic role of PPP3CA in CCA patients. Further studies need to verify these findings and investigate the exact molecular pathways and interaction mechanisms of those proteins identified as playing roles in the development of CCA.

\section{Abbreviations}

CCA: Cholangiocarcinoma; iTRAQ: Isobaric tags for relative and absolute quantitation; PRDX2: Peroxiredoxin2; BGN: Biglycan; LUM: Lumican; PPP3CA: Serine/threonine-protein phosphatase 2B catalytic subunit alpha isoform; IHC: Immunohistochemistry; OS: Overall survival; LC-MS: Liquid chromatography-mass spectrometry; CA19-9: 
Carbohydrate antigen 19-9; TMA: Tissue microarray; SCX: Strong cation exchange; H\&E: Hematoxylin and eosin; DAB: Diaminobenzidine; ABC: Avidin-biotinylated horseradish peroxidase complex.

\section{Supplementary Material}

Supplementary figures and tables. http://www.jcancer.org/v10p3985s1.pdf

\section{Acknowledgments}

The authors are grateful to Dr. Shiyuan Guo, Dr. Jun Zhu, Dr. Hong Zhang, Dr. Dali Xi, and Mr. Caimei Shi for their excellent technical assistance.

Author contributions: Zengwei Tang and Yuan Yang - study concept and design, conducting the experiment, statistical analysis and bioinformatics analysis; interpretation of data, drafting of the manuscript, and critical revision of the manuscript for significant intellectual content.

Jinduo Zhang, Wenkang Fu, and Yanyan Linmaterial collection and interpretation of data.

Gang $\mathrm{Su}$, Yan Li, and Xiaodong Xie-study concept and design and supervision.

Wenbo Meng and Xun Li- study concept and design, funding application and study supervision; critical revision of the manuscript for significant intellectual content.

Financial support: This study was supported by The West Light Foundation of the Chinese Academy of Science (No.90,2015), and Science and Technology Project of China National Petroleum Corporation Lanzhou Petrochemical Company (LZSH201715-2), and The Provincial National Natural Science Foundation of Gansu (17JR5RA273). The funding sources played no roles in the study design, experiment method development, data collection, organization, analysis and interpretation, nor in the manuscript drafting, reviewing or approval.

Ethics approval: The experimental protocol was approved by the Ethics Committee for Human Research, Lanzhou University.

\section{Competing Interests}

The authors have declared that no competing interest exists.

\section{References}

1. Razumilava N, Gores GJ. Cholangiocarcinoma. Lancet 2014; 383:2168-2179.

2. Eckel F, Schmid RM. Chemotherapy in advanced biliary tract carcinoma: a pooled analysis of clinical trials. Br J Cancer 2007; 96:896-902.

3. Khan SA, Davidson BR, Goldin RD, et al. Guidelines for the diagnosis and treatment of cholangiocarcinoma: an update. Gut 2012; 61:1657-1669.

4. Tang Z, Yang Y, Zhao Z, et al. The clinicopathological factors associated with prognosis of patients with resectable perihilar cholangiocarcinoma: A systematic review and meta-analysis. Medicine (Baltimore) 2018; 97(34):e11999.

5. Marin JJG, Lozano E, Briz O, et al. Molecular Bases of Chemoresistance in Cholangiocarcinoma. Curr Drug Targets 2017; 18:889-900.
6. Narimatsu H, Iwasaki H, Nakayama F, et al. Lewis and secretor gene dosages affect CA19-9 and DU-PAN-2 serum levels in normal individuals and colorectal cancer patients. Cancer Res 1998; 58:512-518.

7. Patel AH, Harnois DM, Klee GG, et al. The utility of CA 19-9 in the diagnoses of cholangiocarcinoma in patients without primary sclerosing cholangitis. Am J Gastroenterol 2000; 95:204-207.

8. Macias RIR, Banales JM, Sangro B, et al. The search for novel diagnostic and prognostic biomarkers in cholangiocarcinoma. Biochim Biophys Acta 2018; 1864:1468-1477.

9. Matsuda A, Kuno A, Kawamoto T, et al. Wisteria floribunda agglutinin-positive mucin 1 is a sensitive biliary marker for human cholangiocarcinoma. Hepatology 2010; 52:174-182.

10. Yamaguchi T, Yokoyama Y, Ebata T, et al. Verification of WFA-Sialylated MUC1 as a Sensitive Biliary Biomarker for Human Biliary Tract Cancer. Ann Surg Oncol 2016; 23:671-677.

11. Tang Z, Yang Y, Wang X, et al. Meta-analysis of the diagnostic value of Wisteria floribunda agglutinin-sialylated mucin1 and the prognostic role of mucin1 in human cholangiocarcinoma. BMJ Open 2019;9:e021693.

12. $\mathrm{Xu} \mathrm{F}$, Liu F, Zhao H, et al. Prognostic Significance of Mucin Antigen MUC1 in Various Human Epithelial Cancers: A Meta-Analysis. Medicine (Baltimore) 2015; 94:e2286.

13. Wu WW, Wang G, Baek SJ, et al. Comparative study of three proteomic quantitative methods, DIGE, cICAT, and iTRAQ, using 2D gel- or LC-MALDI TOF/TOF. J Proteome Res 2006; 5:651-658.

14. Polisetty RV, Gautam P, Sharma R, et al. LC-MS/MS analysis of differentially expressed glioblastoma membrane proteome reveals altered calcium signaling and other protein groups of regulatory functions. Mol Cell Proteomics 2012; 11:M111.013565

15. Zeng L, Zhong J, He G, et al. Identification of Nucleobindin-2 as a Potential Biomarker for Breast Cancer Metastasis Using iTRAQ-based Quantitative Proteomic Analysis. J Cancer 2017; 8:3062-3069.

16. Rahnemai-Azar AA, Weisbrod A, Dillhoff $M$, et al. Intrahepatic cholangiocarcinoma: Molecular markers for diagnosis and prognosis. Surg Oncol 2017; 26:125-137.

17. Banales JM, Cardinale V, Carpino G, et al. Expert consensus document: Cholangiocarcinoma: current knowledge and future perspectives consensus statement from the European Network for the Study of Cholangiocarcinoma (ENS-CCA). Nat Rev Gastroenterol Hepatol 2016; 13:261-280.

18. Tang Z, Yang Y, Meng W, et al. Best option for preoperative biliary drainage in Klatskin tumor: A systematic review and meta-analysis. Medicine (Baltimore) 2017; 96:e8372.

19. Choi MH, Lee IK, Kim GW, et al. Regulation of PDGF signalling and vascular remodelling by peroxiredoxin II. Nature 2005; 435:347-353.

20. Agrawal-Singh S, Isken F, Agelopoulos K, et al. Genome-wide analysis of histone $\mathrm{H} 3$ acetylation patterns in AML identifies PRDX2 as an epigenetically silenced tumor suppressor gene. Blood 2012; 119:2346-2357.

21. Wang R, Wei J, Zhang S, et al. Peroxiredoxin 2 is essential for maintaining cancer stem cell-like phenotype through activation of Hedgehog signaling pathway in colon cancer. Oncotarget 2016; 7:86816-86828.

22. Nicolussi A, D'Inzeo S, Capalbo C, et al. The role of peroxiredoxins in cancer. Mol Clin Oncol 2017; 6:139-153.

23. Lee DJ, Kang DH, Choi $\mathrm{M}$, et al. Peroxiredoxin-2 represses melanoma metastasis by increasing E-Cadherin/beta-Catenin complexes in adherens junctions. Cancer Res 2013; 73:4744-4757.

24. Xing X, Gu X, Ma T, et al. Biglycan up-regulated vascular endothelial growth factor (VEGF) expression and promoted angiogenesis in colon cancer. Tumour Biol 2015; 36:1773-1780.

25. Li F, Sethi G. Targeting transcription factor NF-kappaB to overcome chemoresistance and radioresistance in cancer therapy. Biochim Biophys Acta 2010; 1805:167-180.

26. Liu B, Xu T, Xu X, et al. Biglycan promotes the chemotherapy resistance of colon cancer by activating NF-kappaB signal transduction. Mol Cell Biochem 2018; 448(2): 71-76

27. Aprile G, Avellini C, Reni M, et al. Biglycan expression and clinical outcome in patients with pancreatic adenocarcinoma. Tumour Biol 2013; 34:131-137.

28. Jacobsen F, Kraft J, Schroeder C, et al. Up-regulation of Biglycan is Associated with Poor Prognosis and PTEN Deletion in Patients with Prostate Cancer. Neoplasia 2017; 19:707-715.

29. Nishino $R$, Honda $M$, Yamashita $T$, et al. Identification of novel candidate tumour marker genes for intrahepatic cholangiocarcinoma. J Hepatol 2008; 49:207-216.

30. Nikitovic D, Papoutsidakis A, Karamanos NK, et al. Lumican affects tumor cell functions, tumor-ECM interactions, angiogenesis and inflammatory response. Matrix Biol 2014; 35:206-214.

31. Seya T, Tanaka N, Shinji S, et al. Lumican expression in advanced colorectal cancer with nodal metastasis correlates with poor prognosis. Oncol Rep 2006; 16:1225-1230.

32. Ishiwata $\mathrm{T}$, Cho $\mathrm{K}, \mathrm{Kawahara} \mathrm{K}$, et al. Role of lumican in cancer cells and adjacent stromal tissues in human pancreatic cancer. Oncol Rep 2007; 18:537-543.

33. Chen L, Zhang Y, Zuo Y, et al. Lumican expression in gastric cancer and its association with biological behavior and prognosis. Oncol Lett 2017; 14:5235-5240. 
34. Mizuguchi T, Nakashima M, Kato $M$, et al. Loss-of-function and gain-of-function mutations in PPP3CA cause two distinct disorders. Hum Mol Genet 2018; 27:1421-1433.

35. Guerini D, Klee CB Cloning of human calcineurin A: evidence for two isozymes and identification of a polyproline structural domain. Proc Natl Acad Sci U S A 1989; 86:9183-9187.

36. $\mathrm{Li} \mathrm{H}$, Rao A, Hogan PG. Interaction of calcineurin with substrates and targeting proteins. Trends Cell Biol 2011; 21:91-103.

37. Dash R, Su ZZ, Lee SG, et al. Inhibition of AP-1 by SARI negatively regulates transformation progression mediated by CCN1. Oncogene 2010; 29:4412-4423.

38. Tosello V, Saccomani V, Yu J, et al. Calcineurin complex isolated from T-cell acute lymphoblastic leukemia (T-ALL) cells identifies new signaling pathways including mTOR/AKT/S6K whose inhibition synergize with calcineurin inhibition to promote T-ALL cell death. Oncotarget 2016; 7:45715-45729.

39. Gabrovska PN, Smith RA, Haupt LM, et al. Investigation of two Wnt signalling pathway single nucleotide polymorphisms in a breast cancer-affected Australian population. Twin Res Hum Genet 2011; 14:562-567.

40. Campbell JD, Alexandrov A, Kim J, et al. Distinct patterns of somatic genome alterations in lung adenocarcinomas and squamous cell carcinomas. Nature Genetics 2016; 48(6):607-616.

41. Singh AP, Bafna S, Chaudhary K, et al. Genome-wide expression profiling reveals transcriptomic variation and perturbed gene networks in androgen-dependent and androgen-independent prostate cancer cells. Cancer Lett 2008; 259:28-38.

42. Wang Q, Jiang $\mathrm{H}$, Ping $\mathrm{C}$, et al. Exploring the Wnt pathway-associated LncRNAs and genes involved in pancreatic carcinogenesis driven by Tp53 mutation. Pharm Res 2015; 32:793-805.

43. Vellon L, Menendez JA, Lupu R. AlphaVbeta3 integrin regulates heregulin (HRG)-induced cell proliferation and survival in breast cancer. Oncogene 2005; 24:3759-3773

44. Tsai MS, Bogart DF, Castaneda JM, et al. Cyr61 promotes breast tumorigenesis and cancer progression. Oncogene 2002; 21:8178-8185.

45. Loilome W, Bungkanjana $\mathrm{P}$, Techasen A, et al. Activated macrophages promote Wnt/beta-catenin signaling in cholangiocarcinoma cells. Tumour Biol 2014; 35:5357-5367.

46. Boulter L, Guest RV, Kendall TJ, et al. WNT signaling drives cholangiocarcinoma growth and can be pharmacologically inhibited. J Clin Invest 2015; 125:1269-1285.

47. Park J, Tadlock L, Gores GJ, et al. Inhibition of interleukin 6-mediated mitogen-activated protein kinase activation attenuates growth of a cholangiocarcinoma cell line. Hepatology 1999; 30:1128-1133. 